\title{
Study on the seroprevalence of small ruminant brucellosis in and around Bahir Dar, North West Ethiopia
}

\author{
Yeshwas Ferede ${ }^{1}$, Desalegne Mengesha ${ }^{2}$, Gebreyesus Mekonen ${ }^{3}$, and Mussie H/melekot ${ }^{4}$ \\ ${ }^{1}$ Andasa Livestock Research center, PO Box 27, Bahir Dar, Ethiopia \\ ${ }^{2}$ University of Gondar, P. O. Box 196, Ethiopia \\ ${ }^{3}$ Bahir Dar Regional Veterinary Laboratory, P. O. Box 70 Ethiopia \\ ${ }^{4}$ Bahir Dar University, P. O Box 79, Ethiopia, yeshwasferede@yahoo.com_
}

\begin{abstract}
A cross sectional study was carried out from October 2008 to April 2009 to determine the sero-prevalence of brucellosis in small ruminants in and around Bahir Dar, northwest Ethiopia. The sampling method used was purposive sampling technique for districts and simple random for the study animals. A total of 500 serum samples (270 from sheep and 230 from goats) were collected from extensive management system with no history of vaccination. All serum samples were initially screened by Rose-Bengal-Plate Test (RBPT) and positive reactors to $\mathrm{RBPT}(\mathrm{n}=6)$ were further tested by complement fixation test $(\mathrm{CFT})$ for confirmation. Accordingly, the overall prevalence of brucellosis in small ruminants was $0.4 \%(2 / 500)$. Rose Bengal Plate Test detected $6(1.2 \%)$ of the samples as seropositive. Up on further testing by CFT only $2(0.4 \%)$ were positive which were adult goats. The seroprevalence of brucellosis was found higher in females $(0.4 \%)$ than males $(0 \%)$. Although seropositive animals are low in number, it was found out that animals more than 1 year of age were more affected than others. The result of the present study revealed that the seroprevalence of small ruminant brucellosis in the study area was very low. However, the existence of the disease in the study area has possible risk of spread in the future. Accordingly, elimination of positive seroreactors has been recommended to control the spread of brucellosis in these species of animals.
\end{abstract}

Keywords: Brucellosis, Bahir Dar, CFT, RBPT, sheep and goats

\section{Introduction}

The small ruminant population of Ethiopia is estimated to be nearly 23.33 million goats and 23.62 million sheep (IBC, 2004). In the central highlands of Ethiopia, where mixed crop- livestock production system is practiced, 
small ruminants account for $40 \%$ of cash income and 19\% of the household meat consumption (Zelalem Abebe and Flecher, 1993). Sheep and goats are highly adaptable to broad range of environmental conditions. Moreover, low cost of production, requirement of little land and higher prolificacy made them attractive asset for development. Investment in sheep and goats avoid losses due to high inflation rates that are found in unstable economies of many underdeveloped countries like Ethiopia. This is because sheep and goats provide rapid cash turn over (Gatenby, 1991; Steel, 1996).

There is also a growing export market for sheep and goats meat in the Middle Eastern Gulf states and some African countries. At optimum offtake rates, Ethiopia can export 700,000 sheep and 2 million goats annually, and at the same time supply 1,078,000 sheep and 1,128,000 goats for the domestic market (Alemu Yami and Markel, 2008).

In spite of the presence of huge small ruminant population, Ethiopia fails to optimally utilize this resource as a sector. This is because of small ruminant production is constrained by the compound effect of diseases, poor feeding, poor management and low genetic endowment. Among many factors that limit economic return from small ruminants, production diseases stand in the front line. One of such disease that hampers the productivity of small ruminants is brucellosis (Ademosoum, 1994; LMA, 1995).

The genus Brucella is now considered to contain six species: namely, B. abortus, B. melitensis, B. suis, B. ovis, B. canis and B. neotomae. Brucella melitensis (biovars 1, 2 or 3 ) is the main causative agent of caprine and ovine brucellosis and it is highly pathogenic for humans causing one of the most serious zoonoses in the world (OIE, 2000).

Despite the presence of larger population of small ruminants in different regions of Ethiopia, very limited researches have been done on small ruminant brucellosis, even if it is said to be endemic in the country. Therefore, it was found important to study small ruminant brucellosis in and around Bahir Dar. 
Therefore, the objective of the current study was to determine the seroprevalence of small ruminant brucellosis in and around Bahir Dar.

\section{Materials and Methods}

\section{Study area}

The study was conducted in and around Bahir Dar from October 2008 to April 2009. Bahir Dar is located at Northwestern part of Ethiopia, $565 \mathrm{~km}$ away from Addis Ababa. It is the capital city of Amhara National Regional State situated in the southwest direction of Lake Tana. The altitude of this town rages from 1810 to 1850 meter above sea level and temperature ranges from 10 to $38^{\circ} \mathrm{C}$. The area receives mean annual rainfall of $750 \mathrm{~mm}$. The area is marked by two distinct seasons namely; the dry season extending from December to May; and the wet season which extends from June to September. The livelihood of major section of the population in the area depends on crop- livestock mixed farming.

\section{Study animals}

The study animals were indigenous breeds of sheep and goats kept under extensive management system. The sampling included all sheep and goats above 6 months of age with no history of previous vaccination against brucellosis.

\section{Sampling method and survey design}

The sampling method used was purposive for districts and simple random for study animals. The study design was cross-sectional. As there was no study conducted in small ruminant brucellosis in the study area 50\% expected prevalence was considered in sample size determination. The other determinants considered in sample size determination are $95 \%$ confidence internal and $5 \%$ desired absolute precision.

Hence: $-\mathrm{N}=(\mathrm{Zx})^{\underline{2}} \underline{P} \exp (1-\mathrm{Pexp})($ Thrusfield, 1995)

$\mathrm{D}^{2}$

Where: $\mathrm{N}=$ the required sample size

Pexp $=$ the expected prevalence rate $(50 \%)$

$\mathrm{Zx}=$ the value of the required confidence interval (1.96)

$\mathrm{D}=$ desired absolute precision $(5 \%)$ 
Hence, the sample size required as per the above formula was 384 heads of sheep and goats. However, a total of 500 animals (270 sheep and 230 goats) were sampled.

\section{Data collection}

Relevant data of the study animals was recorded along with blood specimens collection. The individual animal details such as the identity of the animal, sex, age, flock size and source of animals were registered. Furthermore, history of abortion and placenta retention were recorded.

\section{Blood sample collection}

About $10 \mathrm{ml}$ of blood was collected from the jugular vein of each sheep and goats using plain vacutaioner tubes and needles. The blood was allowed to clot for 1-2 hours at room temperature, stored horizontally overnight at $4^{\circ} \mathrm{c}$, and then the serum was separated from the clot by centrifugation at 2000-3000 rpm for 10-15 minutes. Then the separated serum was labeled and kept under refrigeration $\left(-20^{\circ} \mathrm{c}\right)$ until tested.

\section{Laboratory procedure/serological tests}

\section{Rose Bengal plate test (RBPT)}

The Rose Bengal Plate Test (PBPT) was used as a screening test for the serum samples collected for the presence of Brucella agglutinins. The test was conducted as per the procedure recommended by Alton et al (1975) and Nilsen and Dunkan (1990). The antigen was obtained from Institute Pourquier, Montpellier, France. This test was carried out at Bahir Dar Regional Veterinary Laboratory.

The interpretation of the results was done according to the degree of agglutination (Nielsen and Dunkan, 1990). Agglutinations was recorded as 0, ,+++ and +++. A score of 0 indicates the absence of agglutination; + indicates barely visible agglutinations; ++ indicates fine agglutination, and +++ indicates coarse clumping. Those samples with no agglutination (0) were recorded as negative while others were recorded as positive.

\section{Complement fixation test (CFT)}

All sera which tested positive by the RBPT were retested using CFT for further confirmation. Standard B. abortus antigen for CFT was used to detect the presence of anti-brucella antibodies in the sera. The test antigen is obtained 
from Addlestone, United Kingdom. The Complement Fixation Test (CFT) was done at the National Animal Health Diagnostic and Investigation Center (NAHDIC).

Sera with strong reaction, more than $75 \%$ fixation of complement $(3+)$ at a dilution of 1: 5 and at least $50 \%$ fixation of complement $(2 \%)$ at a dilution of 1:10 and at dilution of 1:20 were classified as positive (Alton , et al., 1975; OIE, 2004).

\section{Data analysis}

Data was stored in the Microsoft excel spread sheet program and analyzed using STATA 8.0 version software program. The seroprevalence was calculated by dividing the number of CFT positive animals by the total number of animals tested.

\section{Results}

The results of the study are summarized in Table 1 and 2 . Of a total of 500 serum samples tested, six (6) (1.2\%) tested positive for brucellosis infection by the RBPT and only two (2) (0.4\%) of the six were found positive for CFT. All the positive reactors were male goats above one year of age.

Table 1: Seroprevalence of small ruminant brucellosis by species of animals in and around Bahir Dar

\begin{tabular}{llll}
\hline Animal species & Number of sera tested & RBPT positive & CFT positive \\
\hline Caprine & 230 & $4(1.74 \%)$ & $2(0.87 \%)$ \\
Ovine & 270 & $2(0.74 \%)$ & 0 \\
Total & 500 & $6(1.2 \%)$ & $2(0.4 \%)$ \\
\hline
\end{tabular}


Table 2: Serprevalence of small ruminant brucellosis according to sex and age in and around Bahir Dar

\begin{tabular}{lccc}
\hline Risk factor & Number of animals tested & RBPT positive & CFT positive \\
\hline Caprine & 48 & $1(2.08 \%)$ & 0 \\
Male & 182 & $3(1.65 \%)$ & $2(1.10 \%)$ \\
Female & & & \\
Ovine & 60 & 0 & 0 \\
Male & 210 & $2(0.95 \%)$ & 0 \\
Female & 500 & $6(1.2 \%)$ & $2(0.4 \%)$ \\
Total & & & \\
Age & 104 & $1(0.96 \%)$ & 0 \\
Young (<1 year) & 396 & $5(1.26 \%)$ & $2(0.50 \%)$ \\
Adult (> 1 year) & 500 & $6(1.2 \%)$ & $2(0.4 \%)$ \\
Total & & & \\
\hline
\end{tabular}

\section{Discussion}

This study demonstrated that the overall seroprevalence of small- ruminant brucellosis in and around Bahir Dar to be $1.2 \%$ by the RBPT and $0.4 \%$ by CFT. More than half of the sera which tested positive for RBPT, tested negative for CFT. This could be due to cross-reactions between Brucella and other bacteria which share similar epitopes. This prevalence is lower than prevalences recorded in previous studies carried out in different parts of the country; $4.8 \%$ in Afar (Ashenafi Feyissa et al., 2007); 9.7\% in Afar and Somali (Teshale Sori et al., 2007); $1.5 \%$ in sheep and 1.3\% in goats in central highlands of Ethiopia (Tekeleye Bekele and Kassali, 1990); 16\% in Afar Region (Yibeltal, Muhie 2005) and $3.37 \%, 0.11 \%, 3.94 \%$ and $0.49 \%$ from Afar Region, Somali Region, Borena Zone and South Omo Zone, respectively (Melesse Balcha et al., 2006). The difference in the prevalence of brucellosis between the current and previous studies might be attributed to the differences in geographical location, sample size and management systems. In Afar and Somali Region, large numbers of different species of animals are raised on communal pastures under limited watering areas, where as the livestock management in the northwestern Ethiopia is characterized by mixed farming, in which fewer animals are raised separately.

According to the present study, from a total of 500 sera tested, only two goats were seropositive for CFT while no sero-positive sheep was detected. This finding is in agreement with the reports of Omer et al (2000) and Yibeltal 
Muhie (2005) which indicated that goats are at higher risk of acquiring Brucella infection than sheep.

All seroreactors were adult female goats while no sero-positive young goat was found. It has been reported that brucellosis is essentially a diseases of sexually matured animals (Quinn et al., 1999; Radostits et al. 2000). This may result from the fact that sex hormones and erythritol, which stimulate the growth and multiplication of Brucella, tend to increase in concentration with age and sexual maturity (Radostitis et al., 2007).

The present study showed, CFT positive sera were found only in female goats. The absence of male seroreactor animals in this study could probably be due to the small number of males $(\mathrm{N}=108)$ tested as compared to the number of females (n=392). It has also been reported that males are usually resistant than female animals to Brucella infection (Radostitis et al., 1994). Hirsh and Zee (1999) have reported that male animals are less susceptible to infection, due to the absence of erythritol. Moreover, it has been reported that the serological response of male animals to Brucella infection is limited and testes of infected male animals were usually observed to be non reactors or showed low antibody titers (Crawford et al., 1990).

\section{Conclusions}

The result of the present study showed that the sero prevalence of small ruminant brucellosis in the study area was very low. However, the existence of the disease in the study area has possible risk of spread in the future. Accordingly, elimination of positive reactors will provide better considerable success in the control of brucellosis in small ruminant populations in the study area.

\section{Acknowledgements}

The authors are grateful to University of Gondar for funding this study, Bahir Dar Regional Veterinary Laboratory and National Animal Health Diagnostic and Investigation Center (NAHDIC) for their kind cooperation and generous help during the laboratory work. 


\section{References}

Abebe, Z. and Fletcher, I.C. 1993. Small ruminant productivity in Ethiopia mixed farming system. In Proceedings, $4^{\text {th }}$ National Livestock Improvement Conference 13-15 November, IAR, Addis Ababa, Ethiopia.

Ademosoum, A.A. 1994. Constraints and prospects for small ruminant research and development in Africa. ILCA, Addis Ababa, Ethiopia, pp1-5.

Alemu, Y., and Markel, R.C. 2008. Sheep and Goat Production Handbook for Ethiopia. Ethiopia Sheep and Goat Productivity Improvement Program (ESGPIP), Addis Ababa, Ethiopia, pp 2-6.

Alton, G.G., Jones, M.J., and M., Lois, M. and Peitz, D.E. 1975. Serological methods .In: Laboratory Techniques in brucellosis. $2^{\text {nd }} e d$. WHO, Geneva.pp.64-124.

Feyissa, A., Sori, T., Getahun, E., Fikru, Regasa, F., and Yigezu, L., 2007. Distribution of brucellosis among Small ruminants in the pastoral region of Afar. Rev Sie. Tech. Off. Int. Epiz, 26(3), 731-739.

Balcha, M., Sintayehu, G., and Wubetie, A., 2006. Epidemiological surveillance of brucellosis in small ruminants of the pastoral areas of Ethiopia. In: Proceedings of Research Projects Completion Workshop, 1-2 February 2007, Ethiopian Institute of Agricultural Research, Addis Ababa, Ethiopia, pp. 220-221, 233.

Bekele,T., and Kasali, O.B. 1990. Brucellosis in sheep and goats in central Ethiopia. Bull. Anim. Hith. Prod. Afr. 38, 23-25.

Crawford, R., Huber, J.D. and Adams, B.S. 1990. Epidemiology and surveillance. In: Nilsson, K. and Dunkan, J. R. (eds), Animal Brucellosis, CRS Press Inc., Florida, pp. 131-148.

Gatenby, R.M. 1991. Sheep. The Tropical Agriculturalist, Macmillan Education Limited, London and Basingstoke, pp.1-2.

Hirsh, D.C and Zee Y.C.1999. Veterinary Microbiology. Blackwell Science, Cambridge, Massachusetts, pp.196-203.

IBC (Institute of Biodiversity Conservation) 2004. The state of Ethiopia's farm animal genetic resource: country report. A contribution to the first report on the state of the world's animal genetic resources, IBC, May, 2004. Addis Ababa, Ethiopia. 
LMA (Livestock Marketing Authority) 2001. Brief Baseline Information on Ethiopian Livestock Resource Base and Its Trade. Livestock Marketing Authority. Addis Ababa, Ethiopia.

Muhie, Y. 2005. A Sero-prevalence Study of Small Ruminant Brucellosis in Selected Sites of the Afar and Somali Regions, Ethiopia. DVM Thesis, Factuality of Veterinary Medicine, Addis Ababa University, Debre Zeit, Ethiopia.

Nielsen, K., and Dunkan, J.R. 1990. Animal Brucellosis. CRS Press INC, pp 173-179.

OIE, 2004. Manual of Diagnostic Tests and Vaccines for Terrestrial Animals. 5th ed., Office International des Epizootics, Paris, pp 409-438.

OIE, 2000. Manual of Standards for Diagnostic Tests and Vaccines. 4thed., Paris, pp 475-481.

Omer, M. K., Asaw, T., Skjerve, E., Teklegiorgis, T. and Woldehiwot, Z. 2002. Prevalence of antibodies to brucella spp and risk factors related to high-risk occupational groups in Eritrea. Epidemiology and Infection, 129, 85-91.

Quinn, P.J., Carter, M.E., Markl, B. and Carter, G.R. 1999. Clinical Veterinary Microbiology. by Mosby, Edinburgh pp. 261-267.

Radostitis, M.O., Gay, C.C., Hinchcliff, K.W. and Constable, P.D. 2007. Veterinary Medicine, A Textbook of the Disease of Cattle, Horses, Sheep, Pigs and Goats. $10^{\text {th }}$ ed., London, Baillier and Tindal, pp 984-987.

Radostitis, O.M., Gay, C.C., Blood, D.C. and Hinchcliff, K.W. 2000. Veterinary Medicine, A Textbook of Diseases of Cattle, Sheep, Goats, Pigs and Horses. 9th ed., ELBS, Baillier Tindall, London, UK, pp 870-871.

Radostitis, O.M., Blood, D.C. and Gay, C.C. 1994. Brucellosis caused by Brucella spp. In: Veterinary Medicine, A Textbook of the Diseases of Cattle, Horses Sheep, Pigs and Goats, $8^{\text {th }}$ ed., ELBS, London, Baillier Tindall, UK, pp 787-812.

Steel, M. 1996. Goats, The Tropical Agriculturalist. Macmillan Education Limited, London and Basingstoke.pp 1-2.

Sori, T., Muchie, Y., Dagne, A. and Kidanemariam, A. 2007. Sero-prevalence of small ruminant brucellosis in selected districts of Afar and Somalia pastoral areas of Eastern Ethiopia; The impact of husbandry practices. Rev. Vet. Med., pp. 157, 557-563.

Ethiop. Vet. J., 2011, 15 (2), 35-44 
Thrusfield, M. 1995. Veterinary Epidemiology 2ed edition.UK: Backwell scientific Ltd. pp $182-198$.

Yami, A., and Markel, R.C. 2008. Sheep and Goat Production Handbook for Ethiopia, Ethiopia Sheep and Goat Productivity Improvement Program (ESGPIP), Addis Ababa, Ethiopia, pp. 2-6 